\title{
Ensino de "necessidade, eficiência e equidade em saúde": a percepção de especializandos sobre o significado destes conteúdos
}

\author{
Felipe Galvão MACHADO ${ }^{(1)}$ \\ Leonardo CARNUT ${ }^{(1)}$ \\ ${ }^{(1)}$ Faculdade de Saúde Pública, Universidade de São Paulo - USP, São Paulo, SP, Brasil.
}

Recebido: 28 jan 2019 Aceito: 10 fev 2019

Autor de

correspondência:

felipegalvaomachado@gmail.com

Conflito de interesses: Os autores declaram não haver nenhum interesse profissional ou pessoal que possa gerar conflito de interesses em relação a este manuscrito.

\section{Resumo}

O ensino dos conceitos de "necessidade em saúde", "eficiência" e "equidade em saúde" é um desafio para os que se dedicam à docência dos conteúdos das ciências econômicas no âmbito das formações na área da saúde. Não raro, a polissemia dos termos e suas ancoragens epistemológicas, assim como a variabilidade descrita por diversos autores na literatura científica, dificultam a clareza analítica necessária sobre estes conceitos. Nesse sentido, é comum os estudantes que se dedicam a estudar a área da economia da saúde terem uma visão parcelar (eminentemente neoclássica) destes conceitos devido a hegemonia deste enfoque do pensamento econômico na saúde nos últimos anos. Quando essa visão hegemônica não coloniza o pensamento econômico a ser ministrado em sala de aula, o que acontece com frequência é emergência sobre a dúvida em qual conceito repousar a análise decorrente da vasta diversidade e imprecisão que os termos detêm devido ao amplo dissenso sobre eles. Em termos genéricos, pode-se dizer as necessidades em saúde é conceito multidimensional que depende do sistema institucional-administrativo e sua orientação a satisfazê-las na população. Em adição, destaca-se a importância de se repensar a organização do processo de trabalho, gestão, planejamento e construção de novos saberes e práticas em saúde, com o objetivo tornar a atenção mais humanizada traduzindo as necessidades de saúde do usuário em uma oferta de serviço, de acesso à tecnologia e de asseguramento de uma vida salubre. No que se refere ao conceito de eficiência, o seu uso desvinculado de um qualificador que the dê sentido, torna o debate na área totalmente estéril. Quando se trata da aplicação do conceito de eficiência, especialmente em sistemas de saúde universal como é o caso do Sistema Único de Saúde - SUS, faz-se primordial a conjunção entre, no mínimo, três tipos de eficiência: econômica, administrativa e jurídica. Esta articulação se refere aos elementos centrais que garantam a eficiência em seu amplo aspecto conduzindo a um sistema de saúde que assegure as necessidades de forma devidamente ajustada à demanda. No que se refere ao conceito de equidade em saúde, o problema se repete. Equidade em saúde em seu sentido original, em termos marxianos, significa "de cada um segundo suas capacidades, a cada um segundo suas necessidades", entretanto com o avanço da teoria da justiça de John Rawls (justiça como equidade) a perspectiva liberal de equidade foi sendo cunhada tornando o conceito próximo à ideia de focalização. Isto 
alcançou seu auge quando o Banco Mundial em 2006 editou as recomendações para os sistemas de saúde latino-americanos promovendo absorção desta significação do conceito de equidade de forma pouco crítica pela corrente neodesenvolvimentista que, em termos gerais domina o pensamento econômico na saúde coletiva atualmente. É neste cenário em que a clareza sobre estes conceitos torna o ensino da economia da saúde um desafio a ser compreendido e estudado para que o debate sobre esses conceitos se qualifique e ganhe a precisão necessária ao estatuto de cientificidade requerido para o tema. Analisar a percepção dos discentes da especialização em Economia e Gestão em Saúde sobre os conteúdos aprendidos considerado como mais importantes sobre necessidade, eficiência e equidade em saúde. Foi uma abordagem qualitativa para investigação de percepção discente sobre os conteúdos mais importantes da disciplina "Necessidade, Eficiência e Equidade em Saúde". Esta disciplina foi ministrada no terceiro módulo da especialização em Economia e Gestão em Saúde da Faculdade de Saúde Pública da Universidade de São Paulo e teve 20 horas-aula das quais todas foram teóricas. A metodologia de ensino consistiu no uso da Sala de Aula Invertida como uma mescla entre tempestade de ideias, discussões de textos, aula expositiva-dialogada e mapas conceituais. Ao final do componente, foi realizada uma entrevista não-estruturada, ao final de cada uma das 8 aulas. Perguntou-se: quais as partes (conteúdos aprendidos) dessa aula te chamaram mais atenção ou você achou mais importante? Os estudantes respondiam livremente à questão. Analisou-se o material produzido através de análise de conteúdo, por meio da análise textual produzida pelo software IRAMUTEQ. Esta análise é aplicada nos estudos de pensamentos, crenças e opiniões produzidas em relação a determinado fenômeno, tema de investigação, permitindo a quantificação de variáveis essencialmente qualitativas originadas de textos, a fim de descrever o material produzido por determinados sujeitos. Ao final da análise foi possível identificar a percepção dos discentes da especialização sobre o conteúdo estudado. Obteve-se oito variáveis. Cada texto produzido ao final de cada aula foi considerado uma variável de texto. Totalizouse 80 segmentos de texto com 934 formas textuais. Obteve-se 615 palavras únicas (65,58\% do total das formas). As principais palavras mais frequentes sobre o mais importante das aulas foram: aula sobre "Economia, Política e Saúde: os termos do debate na conjuntura brasileira e o SUS" (Aula 1): político $(1,43)$; aula sobre "Necessidade em Saúde - Fundamentos" (Aula 2): necessidade $(4,73)$ e saúde $(0,66)$; aula sobre "Necessidade em Saúde" - Debate atual (Aula 3): necessidade $(3,34)$ e conceito $(0,24)$; aula sobre "Eficiência em Saúde fundamentos" (Aula 4): eficiência $(7,13)$ e conceito $(1,96)$; aula sobre "Eficiência em Saúde e a lógica do Desempenho" (Aula 5): eficiência (1,69); aula sobre "Eficiência em Saúde - qualificações e equilíbrio entre conceitos" (Aula 6): eficiência (1,06); aula sobre "Equidade em Saúde - fundamentos" (Aula 7): equidade $(5,67)$ e social $(1,51)$ e aula sobre "Equidade em Saúde - Debate atual" (Aula 8): equidade $(4,11)$. Na análise de similitude foi possível identificar que os estudantes montaram alguns significados: o primeiro é que a "saúde como 
necessidade é questão técnica essencial", contudo compreenderam que "é importante entender a decisão e a saúde sobre o alcance das necessidades em saúde". Sobre a eficiência eles compreenderam que "ajuda nos resultados e nos recursos empregados" e "informa a gestão". Por fim, sobre a equidade eles compreenderam que "é necessário desconsiderar a focalização para atingir a igualdade". Os discentes reconhecem os termos como importantes, entretanto não discorrem sobre suas conceituações como algo importante. Para eles o debate sobre o alcance das necessidades e a eficiência como princípio da gestão em saúde predominam como mais importante.

Descritores: Ensino; Equidade em Saúde; Determinação de necessidades de cuidado em saúde. 